WellBeing International

WBI Studies Repository

$11-2016$

\title{
Goats Learn Socially from Humans in a Spatial Problem-Solving Task
}

Christian Nawroth

Queen Mary University of London

Luigi Baciadonna

Queen Mary University of London

Alan G. McElligott

Queen Mary University of London

Follow this and additional works at: https://www.wellbeingintlstudiesrepository.org/soccog

Part of the Animal Studies Commons, Comparative Psychology Commons, and the Other Animal Sciences Commons

\section{Recommended Citation}

Nawroth, C., Baciadonna, L., \& McElligott, A. G. (2016). Goats learn socially from humans in a spatial problem-solving task. Animal Behaviour, 121, 123-129.

This material is brought to you for free and open access by WellBeing International. It has been accepted for inclusion by an authorized administrator of the WBI Studies Repository. For more information, please contact wbisr-info@wellbeingintl.org.

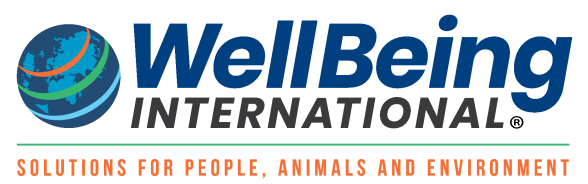


1 Reference: Nawroth, Baciadonna, McElligott (2016) Goats learn socially from humans

2 in a spatial problem-solving task. Animal Behaviour 121: 123-129. doi:

$3 \quad$ 10.1016/j.anbehav.2016.09.004

4

$5 \quad$ Link to published article

6

7

8 Goats learn socially from humans in a spatial problem-solving task

9

10 Christian Nawroth, Luigi Baciadonna, Alan G. McElligott

11 Queen Mary University of London, Biological and Experimental Psychology, School of

12 Biological and Chemical Sciences, London, UK

13

14

15

16

17

18

Corresponding authors

19

CN; Email: Nawroth.christian@gmail.com; Tel: + 44 (0)20 7882 6105; Address: Biological and Experimental Psychology, School of Biological and Chemical Sciences, Queen Mary

21 University of London, Mile End Road, London, E1 4NS, UK

22 AGM; Email: a.g.mcelligott@qmul.ac.uk; Tel: + 44 (0)20 7882 6682; Address: Biological

23 and Experimental Psychology, School of Biological and Chemical Sciences, Queen Mary

24 University of London, Mile End Road, London, E1 4NS, UK 


\section{Highlights}

26 We assessed spatial and social problem-solving abilities in goats using a detour task.

27 Goats did not improve their performance over trials.

28 A single presentation by a human solving the detour resulted in goats solving the task faster.

29 Goats used the same route as the human demonstrator.

30 We provide evidence for social learning from humans in ungulate livestock. 


\section{Abstract}

32 Domestication drives changes in animal cognition and behaviour. In particular, the capacity

33 of dogs to socially learn from humans is considered a key outcome of how domestication

34 shaped the canid brain. However, systematic evidence for social learning from humans in

35 other domestic species is lacking and makes general conclusions about how domestication

36 has affected cognitive abilities difficult. We assessed spatial and social problem-solving

37 abilities in goats (Capra hircus) using a detour task, in which food was placed behind an

38 inward or outward V-shaped hurdle. Goats performed better in the outward than in the inward

39 detour without human demonstration. Importantly, a single presentation by a human solving

40 the inward detour resulted in goats solving the task faster compared to the inward detour

41 without demonstration. Furthermore, 8/9 subjects that received a demonstration used the

42 same route as the demonstrator in the subsequent trial. Thus, goats learn socially from

43 humans. This provides strong evidence for social learning from humans in a domestic species

44 other than dogs.

\section{Keywords}

47 detour task; domestication; social cognition; social learning; spatial cognition 
Animals may acquire new behaviours by either individual and/or social learning. Individual learning occurs through an individual's own experience, but if the environment is unpredictable, individual learning can lead to costly mistakes. By contrast, social learning occurs when the acquisition of behaviour is influenced by observing or interacting with other individuals (Galef \& Laland, 2005; Heyes, 1994), and social animals should have plenty of opportunities to learn from conspecifics. Social learning allows the acquisition of locally adaptive information from conspecifics without having to pay some of the costs associated with individual learning, such as a higher risk of predation (Galef \& Laland, 2005). Animals use a diversity of mechanisms to learn from others, including social facilitation, stimulus and local enhancement, or observational conditioning (Heyes, 1994; Laland, 2004) and social learning is evident in many taxa, including primates (Whiten, 2000), birds, reptiles (Kis, Huber, \& Wilkinson, 2014; Wilkinson, Kuenstner, Mueller, \& Huber, 2010) and fish (Duffy, Pike, \& Laland, 2009).

Research on social learning often focusses on information transfer between conspecifics (Laland, 2004; Andrew Whiten, Horner, Litchfield, \& Marshall-Pescini, 2004), but social learning between members of different species also occurs and may be particularly relevant in human-animal interactions. For example, the ability of canids to solve a task in which they had to go around an obstacle in order to reach a food reward (also known as “detour task”) has been widely investigated (Mersmann, Tomasello, Call, Kaminski, \& Taborsky, 2011; Pongrácz et al., 2001). Interestingly, dogs (Canis lupus familiaris), but not dingoes (Canis lupus dingo), were quicker to find food in a detour task after watching a human demonstrator (Pongrácz et al., 2001; Smith \& Litchfield, 2010). This has led to the assumption that the ability of dogs to learn socially from humans in a detour task is linked to their specific domestication history as companion animals, which led to an increased inclination to interact 
with humans and to pay attention to their communicative cues (Hare, Brown, Williamson, \& Tomasello, 2002). However, others have suggested that the ability of dogs to gain information from humans is more closely associated with ontogeny, e.g. being raised by humans (Udell, Dorey, \& Wynne, 2008).

In general, detour tasks can be used to investigate social learning abilities between conspecifics and heterospecifics (Pongrácz et al., 2001; Rørvang, Ahrendt, \& Christensen, 2015; Wilkinson et al., 2010). However, to date, the effect of a human demonstrator during detour tasks has only been assessed for canids (Mersmann et al., 2011; Pongrácz et al., 2001; Pongrácz, Miklósi, Timár-Geng, \& Csányi, 2003; Smith \& Litchfield, 2010), and therefore broad conclusions about the mechanism that resulted in this ability are not possible. Research on other species, particularly domesticated ones, is crucial in order to evaluate which species perceive and use information provided by humans.

In ungulate livestock, vertical information transfer between individuals (e.g. social learning by offspring from mothers) is important for the development of foraging skills (Glasser et al., 2009; Oostindjer et al., 2011). Still, evidence for horizontal information transfer is scarce. For example, there is no consensus as to whether horses (Equus caballus) are capable of social learning from conspecifics or heterospecifics (Baer, Potter, Friend, \& Beaver, 1983; Clarke, Nicol, Jones, \& McGreevy, 1996; Krueger, Farmer, \& Heinze, 2014). Horses that observed a demonstrator horse manipulating an apparatus to receive a reward also spent more time near the test apparatus. However, observer horses did not learn to manipulate the apparatus more quickly compared to control horses (Ahrendt, Christensen, \& Ladewig, 2012), indicating that they relied on stimulus and/or local enhancement cues from the demonstrators. In another task, observer horses copied specific following behaviours towards humans if the 
demonstrator was a dominant conspecific, whereas this was not the case if the demonstrator horse was subordinate or unknown to the observer (Krueger \& Heinze, 2008).

Less attention has been paid to investigating heterospecific learning in domestic ungulates, e.g. from humans. Held et al. (2001) reported that pigs directly trained by a human experimenter to find food (in one of several corridors) learned to locate the reward. Although pigs learned to visit the correct location, this can only be considered as non-systematic evidence, because data for the training trials were not analysed in detail. More importantly, no control group without a human demonstrator was tested. In addition, there is no evidence for horizontal information transfer or heterospecific social learning in other ungulate livestock species, e.g. goats and sheep. (Baciadonna, McElligott, \& Briefer, 2013; Briefer, Haque, Baciadonna, \& McElligott, 2014). Some of the negative findings might be explained by test subjects not approaching higher-ranking conspecifics or by potential food depletion when a conspecific moves to a rewarded position first (Baciadonna et al., 2013; Rørvang et al., 2015). Methodological constraints are an alternative explanation for the lack of positive results. The test setups may have been too difficult to master for the subjects after only a limited amount of exposure to a demonstrator, e.g. by using a 2-step puzzle box (Briefer et al., 2014). Furthermore, the ability of subjects to pay attention to demonstrators may have been reduced due to presentation times being too long, or the actions performed by the demonstrator may not have been ecologically meaningful to the observer, e.g. pulling a string (Briefer et al., 2014). To solve some of these issues, one solution would be to use attentiongetting behaviours during the task as this has already been shown to improve dogs' detour performance (Pongrácz, Miklósi, Timár-Geng, \& Csányi, 2004). 
122 In previous research, detour tasks with ungulate livestock have focused mostly on the effects 123 of laterality (Versace, Morgante, Pulina, \& Vallortigara, 2007) and/or spatial learning

124 (Osthaus, Proops, Hocking, \& Burden, 2013; see Rørvang et al., 2015 for lack of social

125 learning in horses using a detour task). In our study, we investigated the effect of a human

126 demonstrator on the performance of goats in a detour task and addressed potential

127 shortcomings in previous research. We implemented attention-getting behaviours (i.e. rattling sound of food rewards) to attract the attention of subjects towards the human demonstration of the task (Pongrácz et al., 2004). Furthermore, we examined their flexibility in generalising learned solutions in the spatial problem-solving task. To accomplish this, we presented goats with a series of trials of either inward or outward detour tasks before reversing the detour in a

132 final trial (see Figure 1). Canids solved the outward configuration faster compared to the inward configuration, likely due to an avoidance of corners (Pongrácz et al., 2001; Smith \& Litchfield, 2010). In a similar manner, we expected goats to perform better in the outward compared to the inward task. For this reason, we only gave them a human demonstration in the inward, but not outward detour configuration. This is because we expected a floor effect for their latencies in the outward detour that would have hampered our ability to detect performance improvements after prior human demonstration. Importantly, we expected them to improve in their detour performance once they have observed a human solving the inward task (Pongrácz et al., 2001; Pongrácz, Miklósi, Vida, \& Csányi, 2005). 


\section{METHODS}

Subjects and housing

145 The study was carried out at a goat sanctuary (Buttercups Sanctuary for Goats,

146 http://www.buttercups.org.uk), UK. Initially, we tested 42 adult goats (14 females and 28

147 castrated males, Table 1), which were fully habituated to human presence because of previous research (Baciadonna et al., 2013; Briefer \& McElligott, 2013). They were aged 3-

16 years and of various breeds. Routine care of the animals was provided by sanctuary employees and volunteers. The goats had ad libitum access to hay and were not food restricted before testing.

Procedure

154 The experiment was carried out in a temporary enclosure $(700 \times 500 \mathrm{~cm})$, which we set up within the normal daytime range of the goats. Subjects were tested from 12:00-16:00 during

156 September 2015. The test subjects were visually isolated from other goats, but remained in 157 auditory and olfactory contact with them. Two transparent metal hurdles (height: $120 \mathrm{~cm}$, length: $200 \mathrm{~cm}$ ) were positioned in the middle of the test arena according to the different test conditions (Fig. 1a). Before the start of each training and test trial, the test subjects were kept on a leash by one experimenter to standardize its starting position during the trials. 
Table 1. Characteristics and group assignment of the goats

\begin{tabular}{|c|c|c|c|c|}
\hline Subject & Age & Sex & Breed & Test group \\
\hline a1 & 5 & Male & Toggenburg Mix & Inward detour (no demonstrator) \\
\hline a3 & 4 & Male & Anglo-Nubian & Inward detour (no demonstrator) \\
\hline $\mathrm{a} 4$ & 8 & Female & Saanen Mix & Inward detour (no demonstrator) \\
\hline a6 & 10 & Male & Golden Guernsey & Inward detour (no demonstrator) \\
\hline a7 & 4 & Female & Toggenburg & Inward detour (no demonstrator) \\
\hline a8 & 11 & Female & Alpine & Inward detour (no demonstrator) \\
\hline a10 & 3 & Male & Pygmy & Inward detour (no demonstrator) \\
\hline a11 & 8 & Male & Pygmy & Inward detour (no demonstrator) \\
\hline a12 & 13 & Male & Pygmy & Inward detour (no demonstrator) \\
\hline a13 & 13 & Male & Saanen & Inward detour (no demonstrator) \\
\hline b1 & 5 & Male & Saanen $\mathrm{x}$ Toggenburg & Outward detour (no demonstrator) \\
\hline b2 & 16 & Male & Pygmy & Outward detour (no demonstrator) \\
\hline b3 & 10 & Male & Anglo-Nubian & Outward detour (no demonstrator) \\
\hline b4 & 4 & Female & Toggenburg Mix & Outward detour (no demonstrator) \\
\hline b5 & 9 & Female & Pygmy & Outward detour (no demonstrator) \\
\hline b6 & 15 & Female & Pygmy & Outward detour (no demonstrator) \\
\hline b7 & 8 & Female & Saanen & Outward detour (no demonstrator) \\
\hline b8 & 13 & Female & Angora & Outward detour (no demonstrator) \\
\hline b9 & 3 & Male & Toggenburg x Pygmy & Outward detour (no demonstrator) \\
\hline b10 & 4 & Female & Anglo-Nubian & Outward detour (no demonstrator) \\
\hline $\mathrm{c} 1$ & 7 & Male & Saanen & Inward detour (demonstrator) \\
\hline c2 & 12 & Female & Pygmy & Inward detour (demonstrator) \\
\hline c3 & 8 & Female & Saanen & Inward detour (demonstrator) \\
\hline c4 & 11 & Female & Toggenburg Mix & Inward detour (demonstrator) \\
\hline c5 & 9 & Male & Saanen & Inward detour (demonstrator) \\
\hline c8 & 13 & Male & Pygmy & Inward detour (demonstrator) \\
\hline c9 & 6 & Male & Toggenburg Mix & Inward detour (demonstrator) \\
\hline c13 & 7 & Male & Pygmy & Inward detour (demonstrator) \\
\hline c14 & 3 & Male & Pygmy & Inward detour (demonstrator) \\
\hline
\end{tabular}


167 The initial training period consisted of three trials for every subject before testing. An experimenter baited a transparent plastic box $(10 \times 20 \mathrm{~cm})$ with a piece of dry pasta visible to the subject, positioned the box in front of the hurdles and shook the box once. The subject was then released and was free to explore the arena and the box. After the subject obtained the reward from the box, the subject was brought back to the starting point and a new training trial started. Subjects that went reliably towards the box after three trials were included in the test. Subjects were assigned to one of the following three experimental groups:

Inward detour group (no demonstrator)

176 This inward detour group with no demonstrator consisted of 13 goats. Three goats were excluded because they did not approach the box reliably in the training trials. A second experimenter remained with the goat at the starting pen and prevented it from seeing inside the test arena by using opaque livestock fencing. The first experimenter placed the baited box through the V-shaped hurdles on the inner side of the intersecting angle, not visible to the test animal (Fig. 1b), and shook the box once to draw the subject's auditory attention towards it. When the first experimenter returned to the starting pen, the second experimenter released the goat and started the trial. Both experimenters remained in the starting pen. If the goat was not able to obtain the reward within $60 \mathrm{~s}$, the trial was terminated, and the next trial was started. After three trials the shape of the hurdles was reversed (outward detour; Fig. 1c). The procedure for the fourth trial was the same as reported for the first three trials.

Outward detour group (no demonstrator)

The outward detour group with no demonstrator consisted of 10 goats. Two goats were excluded because they did not approach the box reliably in training trials. Goats in this group 
were exposed to the same test procedure as described for the inward detour group, but in reverse order. There were three consecutive outward detour trials followed by a single inward detour test (trial 4).

\section{Inward detour group (human demonstrator)}

The inward detour group with a human demonstrator consisted of 14 goats. Two goats were excluded because they did not approach the box reliably in training trials. Goats in this group were exposed to the same test procedure as the inward detour group without demonstration, with one exception. Before the first trial started, subjects had the opportunity to watch the first experimenter baiting the box at the training position (i.e. in front of the hurdles) and moving it behind the V-shaped hurdles. During this time, the first experimenter shook the box repeatedly to draw the subject's visual and auditory attention towards the movement (see SEM video). After the experimenter positioned the box, he took the same route back (either left or right of the hurdle). He then moved behind the goat in the starting pen, the subject was released. Half of the subjects received a demonstration using the left side of the hurdle, while the other half received a demonstration using the right side. Subjects did not receive a demonstration prior to subsequent trials. Again, after three trials the shape of the hurdles was reversed (trial 4, outward detour; Fig. 1c).

In all trials, the distance between the entrance of the arena and the intersecting angle of the hurdles was kept the same ( $3.5 \mathrm{~m}$ ). The box was always positioned behind this angle and close to the hurdles. Groups were counterbalanced for breed, age and sex. Some subjects had to be excluded from the final analysis because they were not able to solve the detour in one or more out of the first three trials (inward detour - no demonstrator, 2 subjects; inward detour human demonstrator, 5 subjects). An additional subject had to be removed from the inward 

subjects (inward detour - no demonstrator, 10 subjects; outward detour - no demonstrator: 10 subjects, inward detour - human demonstrator: 9 subjects) were included in the analysis.
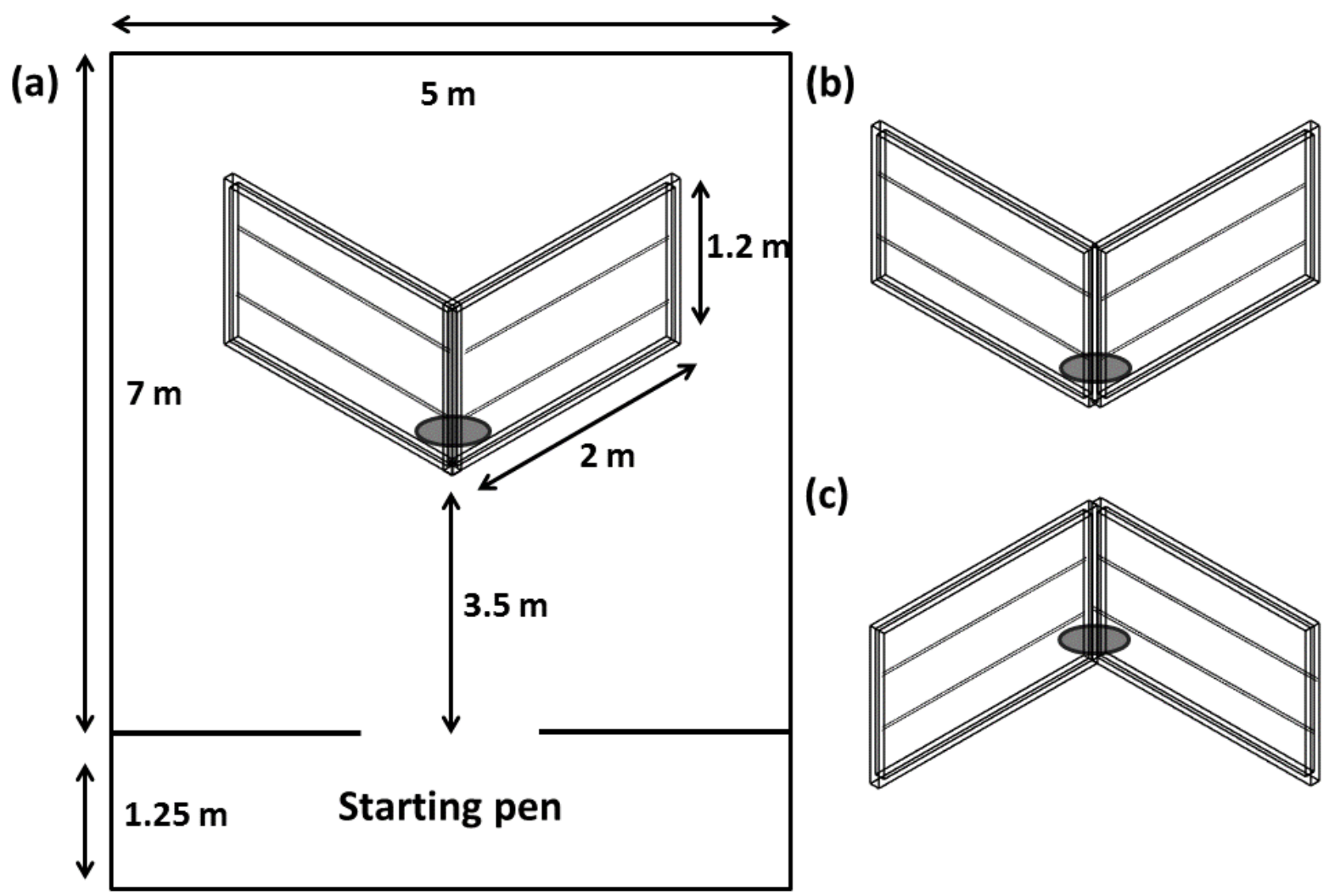

Figure 1 (a) Experimental apparatus (b) Inward detour used with and without human demonstrator (c) Outward detour; the grey circle represents the final position of the box containing the reward

Ethical Note

Animal care and all experimental procedures were in accordance with the ASAB/ABS

Guidelines for the Use of Animals in Research (Association for the Study of Animal

Behaviour, 2016). The study was approved by the Animal Welfare and Ethical Review Board committee of Queen Mary University of London. All measurements were non-invasive, and 
the experiment lasted no more than 10 min for each individual goat. If the goats had become stressed, the test would have been stopped.

\section{Data scoring and analysis}

Latency times the starting point to reach the baited box and the route taken (left or right) were scored live during the test and were also videotaped (Sony HCR-CX190E Camcorder). A test trial started after a goat entered the test arena and finished when the goat either fed from the box within $60 \mathrm{~s}$ or after $60 \mathrm{~s}$ had passed. If a goat did not reach the box containing the food reward, it was led out of the test arena and the latency for the trial was scored with $60 \mathrm{~s}$. A second coder, unfamiliar with the hypothesis, scored the latency and route taken by the subjects of $20 \%$ of the total trials. Inter-observer agreement for latencies (Spearman rank correlation; $\left.r_{\mathrm{s}}=0.979 ; P<0.001\right)$ and for the route taken (Cohen's $k=1.0$ ) was excellent. We used parametric tests (ANOVA, t-tests) for the latency data. The effect of trial number (1-3; within-subject factor) and the experimental group (between-subject factor) was analysed with mixed ANOVA for repeated measures to the within-subject factor. Paired $t$-test were used for each group separately for the comparison of the third and fourth trial (Pongrácz et al., 2001). To analyse whether goats used the same route as the human demonstrator, we used a two-sided binomial test. Concordance in the direction to detour the obstacle over trials 1-3 (left/right) was analysed using Wilcoxon signed rank tests, by comparing the route taken in the second and third trials with the route taken in the first trial. To achieve this, we used the number of subsequent trials in which concordance occurred compared to the direction of the first trial. This mean that concordance could vary between 0 (choosing the opposite route compared to trial 1 in trial 2 and 3) and 2 (choosing the same route compared to trial 1 in trial 2 and 3). The alpha level for all tests was set at 0.05 . 


\section{RESULTS}

255

256

257

We found that the time taken for goats to detour around the obstacle was affected by their experimental group (repeated measures ANOVA: $F_{2.26}=12.17, P<0.001$; Figure 2). We did not find an effect by the trial numbers (trial $1-3 ; F_{2.52}=1.52, P=0.23$ ), or an interaction between both factors on the time to do the detour $\left(F_{4.52}=0.08, P=0.99\right)$. Goats were faster to reach the reward in the first three trials in the outward detour group and inward detour group with a human demonstrator, compared to the inward detour group with no demonstrator (Student-Newman-Keuls post hoc test: all $P<0.05$ ). However, no difference between groups could be found for trial 4 (reverse trial; one-way ANOVA: $F_{2.26}=1.50, P=0.24$ ). In addition, we compared latencies for the third and the fourth (reverse) trial in the three groups to analyse potential performance differences when a new spatial configuration of the detour was presented. Goats did not improve their performance in the inward detour group without a demonstrator when switching towards an outward detour (paired $t$ test: $\mathrm{t}_{9}=1.63, P=0.14$ ), whereas goats in the inward group with a human demonstrator significantly improved their performance from the third towards the fourth trial ( $\left.\mathrm{t}_{8}=2.51, P=0.037\right)$. Furthermore, goats in the outward detour group decreased in their detour performance when confronted with an inward detour $\left(\mathrm{t}_{9}=-4.20, P=0.002\right)$. In addition, we compared the number of subjects that had to be excluded because they were not able to solve the detour in one or more out of the first three trials. The number of subjects did not differ between the three test groups (chisquare test: $\chi^{2}=4.416, P=0.11$ ). Finally, we analysed the route (left or right) goats used in the first three trials. Concordance for detour routes over trials in all three experimental groups was not different from chance level (Wilcoxon signed-rank test; inward detour (no demonstrator): $Z=-0.45, N=10, P=0.66$; outward detour (no demonstrator): $Z=.66, N=$ $10, P=0.32$; inward detour (human demonstrator): $Z=-1.0, N=9, P=0.32$ ), indicating that individual goats were not consistent in the route they used to detour the hurdles. For the 
279 inward detour task with a human demonstrator, 8/9 subjects took the same route as the human

280 demonstrator in the first trial (binomial test: $\mathrm{K}=8, N=9, P=0.04$; two-sided). However,

281 this was not the case for the following trials (all $P>0.5$ ). Thus, human demonstration

282 improved detour performance of goats using an inward spatial configuration, whereas

283 repeated exposure to the same task did not result in improved individual learning (Figure 2).

284

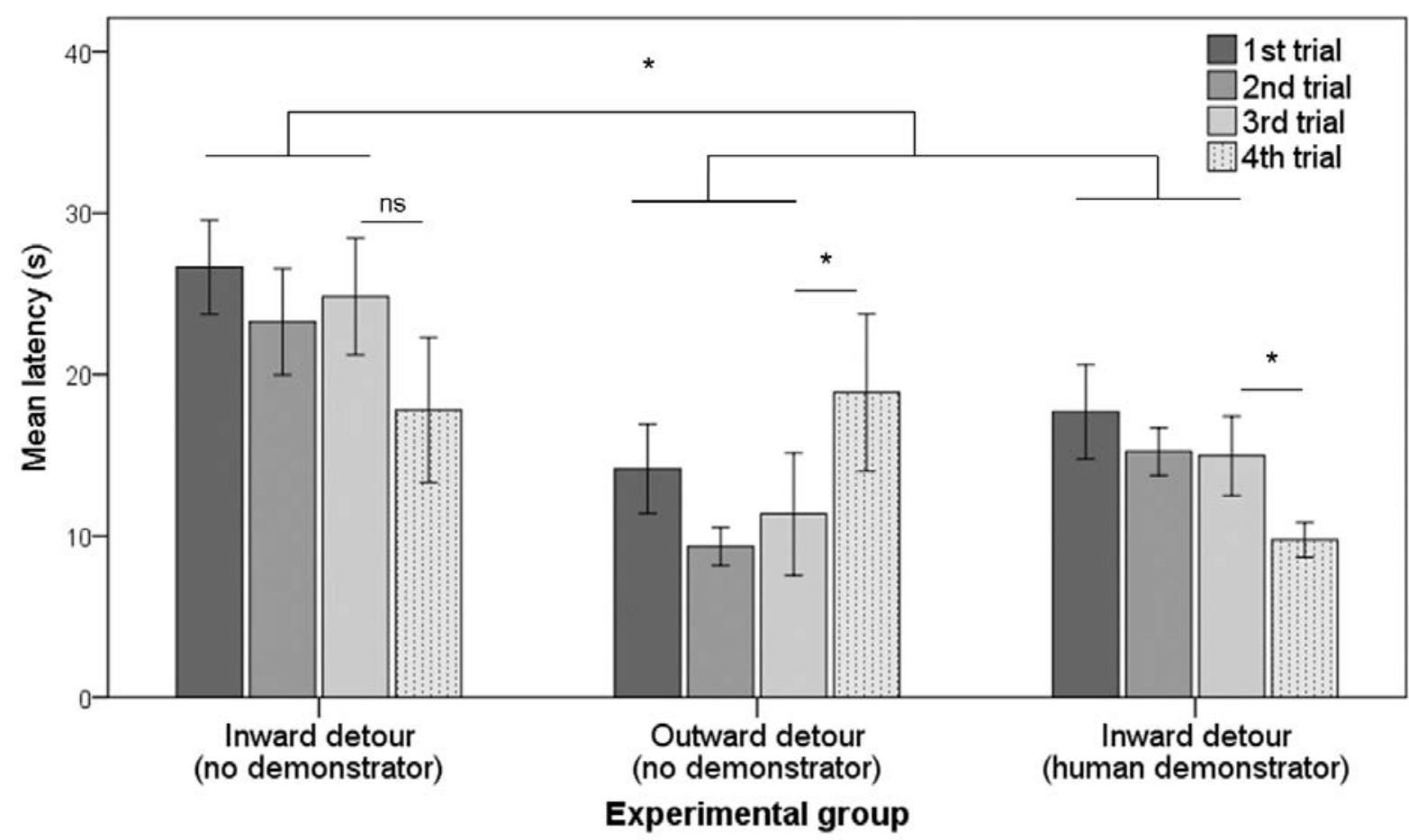

286 Figure 2 Latencies (mean \pm SE) to solve the task in the three experimental groups. * indicate

287 significant differences with $P<0.05$ 


\section{DISCUSSION}

290

291

292

We investigated the ability of goats to socially learn from humans in a spatial problemsolving task. We found that goats that had seen a single demonstration of a human solving an inward detour task had significantly shorter latencies to detour around an obstacle compared to those that did not receive a demonstration. Although no difference between groups in the reverse trial could be found, goats that experienced an inward detour with a human demonstrator significantly decreased their latencies to detour an outward V-shaped obstacle. This was not the case for the group that received the inward detour without a demonstration. Contrary to some results for dogs (Pongrácz et al., 2001), 8/9 goats that received a human demonstration used the same route as the demonstrator in the subsequent trial. However, this was only the case for the first trial immediately after the human demonstration, but not for any subsequent trials. Surprisingly, and in contrast to other results on motor laterality in ungulates, individuals choice of side to detour (left or right) showed no concordance over repeated trials (Leliveld, Langbein, \& Puppe, 2013). We show that animals that have been primarily domesticated for food production are capable of perceiving information from humans, in a similar manner to companion animals such as dogs. Thus domestication might have a much broader impact on cognitive capacities than previously believed (Hare \& Tomasello, 2005; Hare et al., 2005; Nawroth, Brett, \& McElligott, 2016).

There are several possible explanations regarding the mechanisms involved in goats socially learning from humans (Laland, 2004). The most likely explanation is that stimulus or local enhancement have occurred if the action of the demonstrator drew the attention of the goats to particular objects or locations in the environment. The movements of the human demonstrator could have directed the attention of the goat to the path the demonstrator was walking, to the corner of the hurdle where the demonstrator turned back, or to the object that 
was carried behind the hurdle. However, goats may have solved the task simply by following the baited container and not the human demonstrator (Mersmann et al., 2011), or due to a general tendency to follow the path of the demonstrator. This would have resulted in reaching the food reward faster compared to the corresponding non-social condition. Future research should control for this non-social stimulus enhancement by using devices that move a baited container without the help of a human (Mersmann et al., 2011). In addition, social facilitation might have affected goats' performance. The mere presence of the demonstrator could have contributed to the enhanced performance of the goats in the inward group with human demonstration (Zajonc, 1965). Alternatively, because learning took place after only one trial and goats choose the same route as the demonstrator, we cannot exclude the possibility that the goats imitated the detouring behaviour of the human (Huber et al., 2009).

For the spatial component, the initial presentation of the detour ('inward' vs 'outward') had a significant effect on detour latencies. Goats that received the outward V-shaped detour were faster at solving the task compared to subjects that received an inward V-shaped detour. We observed that most subjects in the outward group did not approach the edge of the hurdle, but were instead detouring immediately. This most likely led to the increase in performance found in the outward group because this shortcut was not available for subjects of the inward group. Interestingly, the same pattern was found for dogs (Pongrácz et al., 2001) and it seems likely that goats (like dogs) avoid particular shaped spatial configurations that might resemble corners, like those presented in the outward V-shaped hurdles. These results are confirmed by the goats' performance in the reverse trial. Subjects that experienced an inward detour, either with or without a human demonstrator, in general increased their performance to detour the outward V-shaped obstacle, while goats that received the inward detour after prior exposure to the outward detour decreased in their performance. The lower dropout rate in the outward 
group additionally indicates that the outward formation was perceived as less demanding than the inward formation. Overall, latencies over trials within each experimental group did not differ, indicating no rapid individual learning in the task. This poor individual learning ability in the detour task is in line with findings from canids (Marshall-Pescini, Virányi, \& Range, 2015; Pongrácz et al., 2001; Smith \& Litchfield, 2010).

Our findings on the use of a human demonstrator are in contrast with other research on domestic ungulates that used conspecific demonstrators, either in similar detour tasks (Rørvang et al., 2015), maze learning tasks (Baciadonna et al., 2013), or in operant learning tasks (Baer et al., 1983; Clarke et al., 1996). Several approaches may be relevant to explain the contrast between our results and previous negative findings on social learning in ungulates. Most previous studies used conspecific demonstrators (but see Held et al., 2001 for non-systematic support for heterospecific social learning in pigs), and observers may simply assume that the demonstrator consumed the reward and thus expected depletion of the reward after arrival (Smolla, Gilman, Galla, Shultz, \& Smolla, 2015). Another difference between our findings and previous research in goats is that the delay between the demonstration and test (i.e. the time needed for the experimenter to go from the test arena to the starting pen; approximately 10-15 seconds) was rather short compared to previous studies (Baciadonna et al., 2013; Briefer et al., 2014). This may have improved goats’ ability to socially learn from humans and may also explain why in subsequent trials, in which there were no more demonstrations, they would choose another route. In addition, subjects in previous experiments may have avoided approaching the same location as the conspecific depending on the social rank differences between observers and demonstrators (Baciadonna et al., 2013; Clarke et al., 1996). We assume that our subjects’ improved performance after observing a demonstrator might be also accounted for by our specific procedure used in the test trials. In 
our experiment, the subjects' attention was directed towards the experimenter, who shook the box with the food reward during the demonstration. In most other studies, observer attention may have been lacking until the delivery of the reward at the very end of the test (Briefer et al., 2014; Rørvang et al., 2015). This lack of attention may also account for some negative findings on social learning in ungulates (Briefer et al., 2014; Truskanov \& Lotem, 2015). Moreover, previous work with wolves in the detour task did not involve a social component, reflecting the need for future research that takes into account the impact of domestication on detour demonstration by a human in dogs (Frank \& Frank, 1982; Marshall-Pescini et al., 2015).

\section{Conclusions}

Our results demonstrate that ungulates use information from humans in a spatial problemsolving task. This provides systematic evidence for social learning from humans in a domestic species other than dogs.

\section{FUNDING}

This work was supported by grants from the Deutsche Forschungsgemeinschaft (NA 1233/1-

1) to C.N., and Farm Sanctuary 'The Someone Project' to A.G.M. and C.N.

\section{COMPETING INTERESTS}

The authors declare that the do not have competing interest.

\section{ACKNOWLEDGMENTS}

We would like to thank Jemma Brett for help with data collection and Miriam Ebersbach, 
thank Bob Hitch, Gower McCarthy, Samantha Taylor and all the volunteers at Buttercups

Sanctuary for Goats (http://www.buttercups.org.uk) for their excellent help and free access to the animals. Rest in peace, Ben.

\section{REFERENCES}

Ahrendt, L. P., Christensen, J. W., \& Ladewig, J. (2012). The ability of horses to learn an instrumental task through social observation. Applied Animal Behaviour Science, 139, 105-113. http://doi.org/10.1016/j.applanim.2012.03.004

Association for the Study of Animal Behaviour. (2016). Guidelines for the treatment of animals in behavioural research and teaching. Animal Behaviour, 111, I-IX. http://doi.org/10.1016/j.anbehav.2011.10.031

Baciadonna, L., McElligott, A. G., \& Briefer, E. F. (2013). Goats favour personal over social information in an experimental foraging task. PeerJ, 1, e172. http://doi.org/10.7717/peerj.172

Baer, K. L., Potter, G. D., Friend, T. H., \& Beaver, B. V. (1983). Observation effects on learning in horses. Applied Animal Ethology, 11, 123-129. http://doi.org/10.1016/03043762(83)90121-9

Briefer, E. F., Haque, S., Baciadonna, L., \& McElligott, A. G. (2014). Goats excel at learning and remembering a highly novel cognitive task. Frontiers in Zoology, 11, 20. http://doi.org/10.1186/1742-9994-11-20

Briefer, E. F., \& McElligott, A. G. (2013). Rescued goats at a sanctuary display positive mood after former neglect. Applied Animal Behaviour Science, 146, 45-55. http://doi.org/10.1016/j.applanim.2013.03.007

Clarke, J. V., Nicol, C. J., Jones, R., \& McGreevy, P. D. (1996). Effects of observational learning on food selection in horses. Applied Animal Behaviour Science, 50, 177-184. 

http://doi.org/10.1016/0168-1591(96)01071-4

415

416

417

418

419

420

421

422

423

424

425

426

427

428

429

430

431

432

433

434

435

436

437

438

Duffy, G. A., Pike, T. W., \& Laland, K. N. (2009). Size-dependent directed social learning in nine-spined sticklebacks. Animal Behaviour, 78, 371-375. http://doi.org/10.1016/j.anbehav.2009.05.015

Frank, H., \& Frank, M. G. (1982). Comparison of problem-solving performance in six-weekold wolves and dogs. Animal Behaviour, 30, 95-98. http://doi.org/10.1016/S00033472(82)80241-8

Galef, B. G., \& Laland, K. N. (2005). Social learning in animals: empirical studies and theoretical models. BioScience, 55, 489. http://doi.org/10.1641/00063568(2005)055[0489:SLIAES]2.0.CO;2

Glasser, T. A., Ungar, E. D., Landau, S. Y., Perevolotsky, A., Muklada, H., \& Walker, J. W. (2009). Breed and maternal effects on the intake of tannin-rich browse by juvenile domestic goats (Capra hircus). Applied Animal Behaviour Science, 119, 71-77. http://doi.org/10.1016/j.applanim.2009.02.028

Hare, B., Brown, M., Williamson, C., \& Tomasello, M. (2002). The domestication of social cognition in dogs. Science, 298, 1634-1636. http://doi.org/10.1126/science.1072702

Hare, B., Plyusnina, I., Ignacio, N., Schepina, O., Stepika, A., Wrangham, R., \& Trut, L. (2005). Social cognitive evolution in captive foxes is a correlated by-product of experimental domestication. Current Biology, 15, 226-230. http://doi.org/10.1016/j

Hare, B., \& Tomasello, M. (2005). The emotional reactivity hypothesis and cognitive evolution. Trends in Cognitive Sciences, 9, 464-465. http://doi.org/10.1016/j.tics.2005.08.010

Held, S., Mendl, M., Devereux, C., \& Byrne, R. W. (2001). Behaviour of domestic pigs in a visual perspective taking task. Behaviour, 138, 1337-1354. http://doi.org/10.1163/156853901317367627 
Heyes, C. M. (1994). Social learning in animals: categories and mechanisms. Biological Reviews, 69, 207-231. http://doi.org/10.1111/j.1469-185X.1994.tb01506.x

Huber, L., Range, F., Voelkl, B., Szucsich, A., Virányi, Z., \& Miklosi, A. (2009). The evolution of imitation: what do the capacities of non-human animals tell us about the mechanisms of imitation? Philosophical Transactions of the Royal Society B, 364(1528), 2299-309. http://doi.org/10.1098/rstb.2009.0060

Kis, A., Huber, L., \& Wilkinson, A. (2014). Social learning by imitation in a reptile (Pogona vitticeps). Animal Cognition, 18, 325-331. http://doi.org/10.1007/s10071-014-0803-7

Krueger, K., Farmer, K., \& Heinze, J. (2014). The effects of age, rank and neophobia on social learning in horses. Animal Cognition, 17, 645-655. http://doi.org/10.1007/s10071-013-0696-x

Krueger, K., \& Heinze, J. (2008). Horse sense: Social status of horses (Equus caballus) affects their likelihood of copying other horses’ behavior. Animal Cognition, 11, 431439. http://doi.org/10.1007/s10071-007-0133-0

Laland, K. N. (2004). Social learning strategies. Animal Learning \& Behavior, 32, 4-14. http://doi.org/10.3758/BF03196002

Leliveld, L. M. C., Langbein, J., \& Puppe, B. (2013). The emergence of emotional lateralization: Evidence in non-human vertebrates and implications for farm animals. Applied Animal Behaviour Science, 145, 1-14. http://doi.org/10.1016/j.applanim.2013.02.002

Marshall-Pescini, S., Virányi, Z., \& Range, F. (2015). The effect of domestication on inhibitory control: wolves and dogs compared. PLOS ONE, 10, e0118469. http://doi.org/10.1371/journal.pone.0118469

Mersmann, D., Tomasello, M., Call, J., Kaminski, J., \& Taborsky, M. (2011). Simple mechanisms can explain social learning in domestic dogs (Canis familiaris). Ethology, 
Nawroth, C., Brett, J. M., \& McElligott, A. G. (2016). Goats display audience-dependent human-directed gazing behaviour in a problem-solving task. Biology Letters, 12,

Oostindjer, M., Bolhuis, J. E., Mendl, M., Held, S., van den Brand, H., \& Kemp, B. (2011). 20160283. http://doi.org/10.1098/rsbl.2016.0283

Learning how to eat like a pig: effectiveness of mechanisms for vertical social learning in piglets. Animal Behaviour, 82, 503-511. http://doi.org/10.1016/j.anbehav.2011.05.031

Osthaus, B., Proops, L., Hocking, I., \& Burden, F. (2013). Spatial cognition and perseveration by horses, donkeys and mules in a simple A-not-B detour task. Animal Cognition, 16, 301-305. http://doi.org/10.1007/s10071-012-0589-4

Pongrácz, P., Miklosi, A., Kubinyi, E., Gurobi, K., Topal, J., \& Csányi, V. (2001). Social learning in dogs : the effect of a human demonstrator on the performance of dogs in a detour task. Animal Behaviour, 62, 1109-1117. http://doi.org/10.1006/anbe.2001.1866

Pongrácz, P., Miklósi, Á., Timár-Geng, K., \& Csányi, V. (2003). Preference for copying unambiguous demonstrations in dogs (Canis familiaris). Journal of Comparative Psychology, 117, 337-343. http://doi.org/10.1037/0735-7036.117.3.337

Pongrácz, P., Miklósi, Á., Timár-Geng, K., \& Csányi, V. (2004). Verbal attention getting as a key factor in social learning between dog (Canis familiaris) and human. Journal of Comparative Psychology, 118, 375-383. http://dx.doi.org/10.1037/0735-7036.118.4.375

Pongrácz, P., Miklósi, Á., Vida, V., \& Csányi, V. (2005). The pet dogs ability for learning from a human demonstrator in a detour task is independent from the breed and age. Applied Animal Behaviour Science, 90, 309-323. http://doi.org/10.1016/j.applanim.2004.08.004

Rørvang, M. V., Ahrendt, L. P., \& Christensen, J. W. (2015). Horses fail to use social 
learning when solving spatial detour tasks. Animal Cognition, 18, 847-854. http://doi.org/10.1007/s10071-015-0852-6

Smith, B. P., \& Litchfield, C. A. (2010). How well do dingoes, Canis dingo, perform on the detour task? Animal Behaviour, 80, 155-162. http://doi.org/10.1016/j.anbehav.2010.04.017

Smolla, M., Gilman, R. T., Galla, T., Shultz, S., \& Smolla, M. (2015). Competition for resources can explain patterns of social and individual learning in nature. Proceedings of the Royal Society B, 282, 20151405. http://doi.org/10.1098/rspb.2015.1405

Truskanov, N., \& Lotem, A. (2015). The importance of active search for effective social learning: an experimental test in young passerines. Animal Behaviour, 108, 165-173. http://doi.org/10.1016/j.anbehav.2015.07.031

Udell, M. A. R., Dorey, N. R., \& Wynne, C. D. L. (2008). Wolves outperform dogs in following human social cues. Animal Behaviour, 76, 1767-1773. http://doi.org/10.1016/j.anbehav.2008.07.028

Versace, E., Morgante, M., Pulina, G., \& Vallortigara, G. (2007). Behavioural lateralization in sheep (Ovis aries). Behavioural Brain Research, 184, 72-80. http://doi.org/10.1016/j.bbr.2007.06.016

Whiten, A. (2000). Primate culture and social learning. Cognitive Science, 24, 477-508. http://doi.org/10.1016/S0364-0213(00)00027-6

Whiten, A., Horner, V., Litchfield, C. A., \& Marshall-Pescini, S. (2004). How do apes ape? Animal Learning \& Behavior, 32, 36-52. http://doi.org/10.3758/BF03196005

Wilkinson, A., Kuenstner, K., Mueller, J., \& Huber, L. (2010). Social learning in a non-social reptile (Geochelone carbonaria). Biology Letters, 6, 614-616. http://doi.org/10.1098/rsbl.2010.0092

Zajonc, R. B. (1965). Social Facilitation. Science, 149, 269-274. 
http://doi.org/10.1126/science.149.3681.269

515 